\title{
Factors Contributing to High HIV Prevalence in Majang Zone, Southwest Ethiopia: What Lies Beneath the Tip of the Iceberg?
}

\author{
Qaro Qanche (D) \\ Wondimagegn Wondimu (iD) ${ }^{2}$ \\ Adane Asefa iD ${ }^{2}$ \\ Tewodros Yosef iD ${ }^{2}$ \\ Gachana Midaksa (ID) \\ Tadesse Nigussie (iD ${ }^{3}$ \\ 'Department of Public Health, School of \\ Public Health, College of Medicine and \\ Health Science, Mizan-Tepi University, \\ Mizan Aman, Southern Nations, \\ Nationalities and Peoples Regional State, \\ Ethiopia; ${ }^{2}$ Department of Epidemiology \\ and Biostatistics, School of Public Health, \\ College of Health Science, Mizan-Tepi \\ University, Mizan Aman, Southern \\ Nations, Nationalities and Peoples \\ Regional State, Ethiopia; ${ }^{3}$ Department of \\ Public Health, College of Health Science, \\ Salale University, Salale, Oromia Regional \\ State, Ethiopia
}

Background: Despite the tremendous efforts made, HIV epidemic has been continuing to be a public health threat and one of the leading causes of death in sub-Saharan African countries. Gambella region is a high prevalence region persistently exhibiting the highest share of HIV cases in Ethiopia. Thus, the objective of this study was to explore factors contributing to high HIV prevalence in the Majang zone of Gambella region, Southwest Ethiopia.

Methods: A descriptive qualitative study was conducted in the Majang zone of Gambella region, Southwest Ethiopia from March to May 2019. A heterogeneous purposive sampling technique was employed to recruit key informants and focused group discussion participants. Eighteen key informant interviews and 9 focused group discussions were conducted $(\mathrm{N}=90)$ with health professionals, youth, mothers, and community elders. An interview guide developed through an extensive literature review was used to elicit information from the study participants, and data were collected by the investigators themselves with the help of local guides. Data were audio recorded, transcribed, translated, coded, and analyzed thematically, assisted by Atlas.ti 7.5.16 software. Trustworthiness of the data was ensured through data triangulation, prolonged engagement, member checking, and inquiry audit in which findings were audited and verified by qualitative research experts. Ethical clearance was obtained from the Institutional Review Board of Mizan Tepi University, and written signed informed consent was obtained from all the participants prior to conducting the interviews.

Results: A total of 90 individuals have participated in this study. Several factors appear to underlie the sustained high prevalence of HIV in the study area and were organized into five major themes: 1) government-related factors, 2) community perception towards HIV, 3) substance use, 4) socio-cultural factors, and 5) movement of people.

Conclusion: Low government attention towards HIV prevention and control activities, low perceived severity of HIV, substance use, socio-cultural factors, and high movement of people appear to inform the understanding of factors contributing to HIV risk in Majang zone. The sociocultural factors include the use of "Tifo Bet" and social support for polygamy. These findings loudly call for the governmental, non-governmental, and private sectors to reconsider and strengthen strategies for the prevention and control of HIV in the study area.

Keywords: contributing factors, high HIV prevalence, focus group discussion, HIV prevention, Majang zone, Southwest Ethiopia

\section{Background}

Human immunodeficiency virus (HIV) continues to be a major global public health issue and the leading cause of deaths in the world including sub-Saharan Africa. ${ }^{1}$ In
Correspondence: Qaro Qanche
Tel +25I 916401623

Email qaroqanche@gmail.com 
2019, 38 million people were living with HIV, and there were 1.7 million new HIV infections and 690,000 HIVrelated deaths, globally. ${ }^{2}$

Though HIV prevalence is reducing over time, the global trend shows that HIV prevalence is still the highest (3.6\%) in sub-Saharan Africa. ${ }^{3}$ In sub-Saharan Africa, there were 25.7 million people living with HIV, and 440,000 lives were lost to HIV-related illnesses in 2019. Every day, 4500 new HIV infections occur worldwide, out of which about $59 \%$ are in sub-Saharan Africa. ${ }^{2}$

There are 46 countries with the highest HIV prevalence (greater than $0.7 \%$ of global prevalence) in the world, of which 35 are African countries including Ethiopia. ${ }^{3}$ In Ethiopia, according to the UNAIDS data 2020, although new HIV infections and related deaths show slight declines over the past one decade, the number of people living with HIV remained the same, standing at 670,000 from 2010 to $2019 .^{2}$

National HIV prevalence in Ethiopia is $0.9 \%$, and the epidemic is heterogeneous by sex, geographic areas, and population groups. Among women and men combined, HIV prevalence is seven times higher in urban areas than in rural areas (2.9\% versus $0.4 \%)$. HIV prevalence is $3.6 \%$ among women in urban areas compared with $0.6 \%$ among women in rural areas. Looking at HIV prevalence by regional states, it is the highest in the Gambella region (4.8\%), followed by Addis Ababa city (3.4\%), Dire Dawa city (2.5\%), and Harari region (2.4\%). ${ }^{4}$

In recent years, the international community has developed an ambitious goal of ending the HIV epidemic as a public health threat by $2030 .^{5}$ In this regard, taking the baseline of 2010, fast-track interim benchmarks were targeted to reduce new HIV infection and HIV-related deaths by $75 \%$ by $2020 .^{6-8}$ To this end, Ethiopia has adopted the global 90-90-90 HIV prevention targets by 2020 . According to this plan, by $2020,90 \%$ of people living with HIV will know their HIV status, $90 \%$ of people with diagnosed HIV infection will receive antiretroviral therapy, and $90 \%$ of all people receiving antiretroviral therapy will have their viral load suppressed. ${ }^{6}$

These targets are merely focused on the identification and treatment of already infected people and pay less attention to primary prevention in the community. It is essential to explore the deep-rooted behavioral and structural factors in the community that contribute to HIV infection and design strategies to tackle these factors along with secondary prevention strategies in order to be able to realize the achievement of the global ambitious goal for ending the HIV epidemic as a public health threat by 2030 .

Gambella regional state has, by far, the highest HIV prevalence in the country, which is $4.8 \%$. Indeed, this figure only represents the tip of the iceberg of the problem and the reasons behind it are not well known and described. Therefore, the objective of this study was to explore factors contributing to this sustained high HIV prevalence in Majang zone of the Gambella region, Southwest Ethiopia.

Different studies conducted in different geographic regions have identified multiple factors contributing to HIV infection. Some of these contributing factors include unprotected sexual intercourse, having multiple sexual partners, casual sex, sex under the influence of alcohol, and paying or receiving goods or money for sexual intercourse. $^{9-12}$

A concurrent quantitative study conducted in the Majang zone among adults on the determinants of knowledge and attitude towards HIV prevention methods (which was conducted by the same authors at the same time as this study) has revealed that secondary education and above, and positive HIV prevention attitude were the independent determinants of HIV prevention knowledge. Additionally, the study has also identified that older age group and good HIV prevention knowledge were significantly associated with a positive HIV prevention attitude. $^{13}$

These are proximal factors, which are very common, well addressed, and well known so far. However, more distally underlying factors, which may be very specific to the local contexts and embedded within the culture of the local community need to be explored in-depth and acted upon. No previous studies have been conducted in the study area in this regard and our study intends to explore such distally underlying local contextwise factors for the high prevalence of HIV in Majang zone.

\section{Methods}

\section{Study Design, Setting, and Period}

A descriptive qualitative study was conducted from March to May 2019 to explore factors contributing to the sustained high HIV prevalence in the Majang zone, Southwest Ethiopia. Majang zone is located in Gambella regional state in the Southwest of the country. This zone was purposely selected for this study because it reports the highest number of estimated new HIV infections in the 
general population annually on repeated occasions when compared to other zones in the region. The zone has three districts, namely Godere, Mengeshi, and Meti. Based on the population projection by the central statistical agency (CSA) for 2014-2017, the zone had a total population of 79,041 , of whom 40,896 were men.

\section{Study Participants and Sampling}

Participants of this study were residents above 18 years old (age range of 18-70 years) and lived in the locality for at least six months. A sample of 90 participants (39 males and 51 females) were recruited from health professionals, youth, mothers, and community elders to conduct this study.

A heterogeneous purposive sampling technique was employed to recruit key informants (KIs) and participants of focused group discussions (FGD) considering maximum variability with the assumption of obtaining "rich" information. Further sampling was guided by the emerging concerns or issues from the preceding interviews.

Accordingly, a total of 18 key informant interviews (KIIs) were conducted. The KIs were health professionals, head of zonal health office, head of Woreda health office, and community elders. Similarly, 9 FGDs were conducted (4 FGDs with youth, 3 FGDs with mothers, and 2 FGDs with community elders). Overall, a total of 72 participants were involved in all the FGDs.

\section{Data Collection Method}

An interview guide developed through an extensive literature review was used to elicit information from the study participants. The data were collected by the investigators themselves using local guides. The KIIs and FGDs were tape-recorded along with handwritten field notes.

\section{Data Analysis}

The audiotaped data were transcribed, translated and coded for thematic analysis. Finally, some of the quotes that exemplify the themes were selected and used in the interpretation of results. All the procedures were supported by Atlas.ti version 7.5.16 software.

\section{Trustworthiness}

Different techniques were used to ensure the credibility, dependability, transferability, and confirmability of the study. The diversity of participants involved in the FGDs and mixing data from KIIs was aimed at maintaining data triangulation.
Researchers from different disciplines have participated in data analysis and interpretations. The authors have stayed in the field for a long period during the recruitment of study participants, data collection, and member checking.

Data collection was conducted after taking consent from each participant and making rapports. Debriefing sessions were held by note-takers about the overall processes at the end of each interview and discussion.

The analyzed and interpreted data were checked against audio-tapped data and field notes before producing the final report. In addition, the analyzed and interpreted data were commented on by colleagues. Findings were also audited and verified by colleagues and qualitative research experts.

\section{Ethical Consideration}

This study was conducted in accordance with the Declaration of Helsinki. Ethical clearance was obtained from the Institutional Review Board of Mizan Tepi University, and all necessary permissions were secured from the local administrative offices. Written and signed informed consent was obtained from all the participants and this consent includes permission for publication of anonymized responses. In addition, permission for audio recording was obtained before the data collection.

\section{Results}

\section{Socio-Demographic Characteristics of Participants}

A total of 90 individuals have participated in this study. One-third of the participants of FGDs were within the age range of 18-24 (Table 1).

\section{Factors Contributing to High HIV Prevalence in Majang Zone}

The factors that were identified to be contributing to high HIV prevalence in Majang zone were organized into five major themes: 1) Government-related factors, 2) Community perception towards HIV, 3) Substance use, 4) Socio-cultural factors and 5) Movement of people.

\section{Government and/or NGOs Related Factors Low Attention for HIV}

Reduced attention of the government to tackle the disease was identified as one of the main reasons for the sustained high prevalence of HIV in the Majang community. 
Table I Characteristics of Study Participants, Majang Zone, 2019

\begin{tabular}{|c|c|c|c|}
\hline \multicolumn{2}{|c|}{ Category of Participants } & \multirow{5}{*}{$\begin{array}{l}\text { Number } \\
1 \\
3 \\
6 \\
8\end{array}$} & \multirow{5}{*}{$\begin{array}{l}\text { Age } \\
42 \\
29-38 \\
26-45 \\
58-70\end{array}$} \\
\hline KII participants & Head of zonal health department & & \\
\hline & Head of district health office & & \\
\hline & Health professionals & & \\
\hline & Community elders & & \\
\hline FGD & Youth (males) & 2 groups ( 7 and 8 participants in the first and second groups, respectively) & $18-24$ \\
\hline participants & Youth (females) & 2 groups (6 and 9 participants in the first and second groups, respectively) & $18-24$ \\
\hline & Women (mothers) & 3 groups ( 8,9 , and 9 mothers in the first, second, and third groups, respectively) & $30-45$ \\
\hline & Community elders & 2 groups ( 8 participants in each group) & $50-68$ \\
\hline \multicolumn{2}{|c|}{ Total number of participants } & \multicolumn{2}{|l|}{90} \\
\hline
\end{tabular}

Mentioning the previous efforts by the government and non-governmental organizations like community mobilizations, training, and empowerment for HIV prevention, the participants pointed out that there is discontinuance of such support activities at the current time. Consequently, many people in the area failed to follow the recommended HIV preventive behaviors.

For instance, one of the KIs said:

... government has now completely forgotten the issue of HIV. In the past time, every talk was about HIV but now nobody raises about it. (52 years old, community elder)

Another KI added to this point by saying:

Because of shortage of donors financing towards HIV since couple of years and inability of domestic financing sources to fill the gap, HIV is getting less attention these days when compared to the past times. The government is already stretched by the current political and economic crises and channels huge part of its budget to contain these crises. As a result, HIV is not on the government's top priority agenda and is being almost forgotten. (42 years old, KI)

\section{Shifting Attention to Other Programs}

The majority of the KIs and FGD participants stressed the diverting of the government's attention from HIV-related programs to other programs. As a result, many people have started to perceive that the disease has gone from the area. For example, one of the FGD participants said:

... this time what is more important for this community is not politics or other things; first, the issue of HIV should be dealt with. Other things will come later. The government should give more emphasis on HIV like in the previous times ... . (36 years old, mother, FGD)

Similarly, one of the KIs said:
Nowadays, HIV is not a priority area for the government. The government is not allocating adequate resources to tackle the disease in the community. No NGOs are working on this issue and there is no special training provided from the government regarding HIV. (32 years old, male, health professional, KI)

\section{Community Perception Towards HIV}

Wrong community perception towards HIV (low perceived severity of HIV) was also identified as one of the major contributing factors to the high prevalence of HIV in Majang zone. Low perceived severity of the disease seems to underlie low preventive behavior for oneself and/or others. In line with this, many FGD participants and key informants disclosed the fact that the community perceives the disease as simple as or as mild as a common cold or typhoid fever and nobody worries about it.

For instance, one of the FGD participants said:

... they (the community) are not even considering HIV as a disease; many people perceive it as simple as a common cold. ... So, even, people living with HIV are not taking care for themselves and they are so reluctant in discharging their responsibility for halting transmission of the disease to noninfected persons. (40 years old, mother, FGD)

As a result, the intention to know one's HIV status or that of their sexual partner is very low in the area. Even, those who have tested for HIV do not disclose their test result for their sexual partners. Dictating normalization of multiple and premarital sexual practices in the area, many participants stressed the habit of hiding one's HIV status from their sexual partners.

Another participant added that:

... they have no habit of checking HIV status before starting a sexual relationship, and the youth have the 
habit of premarital sexual practice. (50 years old, community elder, FGD)

Another key informant pointed it clear that:

Most of the community members, specially youth, are considering the disease the same as other diseases because any person living with HIV can live a normal life and it is not leading people to severe illness or death like in the previous times. This is due to the fact that because of the availability of HIV drugs nowadays people living with HIV are leading healthy normal life and do not get severely ill and die. (61 years old, community elder, KI)

\section{Substance Use}

Alcohol, chat, and hashish are the main substances commonly used in the area. The availability of chat and hashish houses led the community members to substance abuse. Although HIV can affect anyone, the risk of infection is relatively high among substance users as it increases the likelihood of risky sexual behavior due to increased loss of judgment.

These problems are increased among people using a combination of substances like alcohol with other substances. Most substance users in the Majang zone consume at least two of the most common addictive substances simultaneously. Alcohol drinkers are either cigarette smokers or chat chewers, or hashish users, or a combination of these. By explaining the high magnitude of substance use, the participants disclosed subsequent risky sexual behaviors practiced in the area, including rape.

One of the FGD participants described this situation as:

... There are some HIV patients who are taking alcohol and getting drunk which makes them unable to remember to take their medications on time ... . (44 years old, mother, FGD)

Another mother in the same group added that:

... A person who is addictive is mad and involves in multiple sexual practices. For your surprise, because of excessive alcohol use and addiction, rape has occurred in our locality a couple of months ago ... . (38 years old, mother, FGD)

Furthermore, another key informant said that:

... Youths who are users of alcohol are users of chat and cigarette as well ... . (60 years old, community elder, KI)

Since hashish use is illegal, there were some reported interventions to eliminate or reduce the use of the substance, but still hashish houses are common in different towns of the zone.

The quote of one of the KIs supported this reality.

... Last month, around 90 hashish smuggling houses are closed and burned by policemen; but still there are some remained houses ... . (a 32-year-old, male, health professional, KI)

But one community elder litigated the interventions as follows:

... Many times police announce that they have collected hashish and burned it and also arrested the owners of substances. But when it was checked, no one was arrested in reality .... (A 61-year-old community elder, KI)

\section{Socio-Cultural Factors}

Living in Isolated Houses (Using "Tifo Bet”)

In Majang culture, unmarried male youth build their own separate houses, locally named as "Tifo Bet". "Tifo Bet" is a separate house built by unmarried male youth from local materials and roofed by grass. It is built in a far place from their parents' house. Its primary purpose is to introduce male youth to exercise and get familiarity to lead their future independent life.

The presence of "Tifo Bet" in the Majang community seems to appear as the main contributing factor for the high prevalence of HIV in the area. Male youth take this independence as an opportunity to exercise multiple unsafe sexual practice with local youth girls. "Tifo Bet" helps them to keep their sexual relations secret from the sight of parents and other people. Girls come to the "Tifo Bet" by their own will after acquiescing with the owner of the house. Hence, no force or rape is involved. The worst thing here is engaging in unsafe sexual practices with multiple partners and premarital sex without using a condom or knowing the HIV status of his or her sexual partners.

The majority of the FGD participants and key informants emphasized the contribution of "Tifo Bet" for the high prevalence of HIV among the Majang community.

The use of 'Tifo Bet' has been long existed for centuries in the Majang culture. What is creating problem now is the presence of HIV. In the past there was no HIV and every thing was safe. I think it is important to educate youth about safe sexual practice including condom use. (24 years old, male youth, FGD)

The worst thing is that unsafe sexual practice is performed with multiple girls. No HIV test or condom is used. 
Unsafe sex is performed without knowing the status of each other ... . (65 years old male, community elder, KI)

Intergenerational disassortative sexual practice, where older men have sex with young women, is one of the particular findings that has a noteworthy impact on the sustained high prevalence of HIV. The majority of the KII and FGD participants pointed out that the owner of the "Tifo Bet" collaborates with his friends and other people coming from nearby towns to have sexual intercourse with many local female youth in exchange for money and goods. Girls practice sexual intercourse with these strangers of unknown HIV status. The girls, once contracted the disease from these strangers, can further transmit the disease to other people upon subsequent unsafe sexual contact with local boys.

For instance, an FGD participant mother said:

... Sometimes the owner of "Tifo Bet" allows the house for his friends and others to have sex in it. It is also common that those who come from the towns for government work also use this house to have sex with local girls. Those who come from towns give small things like soap, lotions, or money to the girls in exchange for sex. The girls are easily convinced by them because these men have higher educational and economic status. The girls do not know the HIV status of those strangers, but they only give their willingness for economic gains ... . (40 years old, mother, FGD)

Another KI added by saying:

... Majority of the youths catch HIV in these houses. Adult men coming from nearby towns to the rural kebeles for their private businesses or office duties give soap, lotions, or small amounts of money for the girls and take them to the 'Tifo Bet' to have unsafe sexual intercourse. These people coming from the towns are suspected to be HIV positive and they are infecting those innocent girls. Then, these girls will have sex with local boys and the spread continues. Every sexual contact is unsafe because they do not use a condom. (36 years old, female health professional, KI)

\section{Extramarital Sexual Practice}

Conducting sexual intercourse with someone who has no marital relation to oneself is mentioned as one of the leading factors for sustained HIV prevalence in the Majang zone. Emphasizing the unlimited number of sexual intimacies a married person may have in the area, the majority of the FGD participants and key informants explained their worries regarding how to tackle these intertwined problems. This was further aggravated by the embarrassment of many people for using a condom. For instance, a 30-year-old health professional explained it like this:

.... Married men engage in sexual practice with unlimited partners. We also believe that this has greatly aggravated the spread of HIV infection in the community ... . (40 years old Male health professional, KII)

Another FGD discussant added to this point by saying:

... Most of the married people are not faithful. And they practice unsafe sex ... . (24 years old, female youth, FGD)

Low utilization of condom in the community was another factor related to the high prevalence of HIV in the zone. Most of the key informants explained that people are not using condom appropriately for different reasons.

For instance, one KI said:

People are not familiar with condom. They don't know it. They are embarrassed to use it. Even those who are married cheat their partners without using condom. years old, male, health professional, $\mathrm{KI}$ )

\section{Polygamy}

Another socio-cultural related factor for the sustained prevalence of HIV in the Majang community is polygamy. The majority of the study participants explained that marrying more than one wife is widely practiced in the area and has contributed to HIV transmission.

One of the FGD participants explained it as follows:

... Marrying two or three wives is customary in this area and it is too dangerous ... . (42 years old, Mother, FGD)

Another key informant also stated this issue as follows:

......Double marriage is very common in this area. The community also supports double marriage. They consider it as a measure of their wealth ... . (28 years old, male health professional, KI)

\section{High Movement of People}

Notably high movement of people in the Majang zone contributes significantly to the high prevalence of HIV in the area. Many individuals move from place to place for reasons like mass sports events, religious conferences, college studies, and labor works like mining, coffee harvesting, and business activities. 
Individuals, especially youth, move to other places and engage in risky sexual activities since they are free from the control of their parents. For zonal-level sport competitions, youth boys and girls are recruited from different rural Kebeles to attend the festivals in towns. After the completion of the competition, they do not return immediately to their parents as they commence new unsafe sexual relationships.

Similarly, religious conferences are also among the moments that create conducive environments for youth to get together, to become free from the control of their families, and be involved in unsafe sexual practices.

A 40-year-old community elder FGD discussant described the condition as follows:

Mainly youth who are coming from rural areas for mass sports and religious conferences are playing a key role for the spread of the disease since they become free from the control of their parents to have a conducive free time to engage in unsafe sexual practices. (40 years old, community elder, FGD)

In the town, there are different public and private colleges where many students are attending their college studies. Most students coming from the rural districts and Kebeles live in rented rooms in the town. Being free from their parents' control allows them to start new sexual practices. As a result, these students may bring the infection from their locality or become newly infected from the town and transmit it to others upon returning back to their residence. On top of this, the students have a poor practice of HIV preventive behaviors like condom use.

For instance, one FGD participant expressed the scenario in this way:

... As the college students are far from their family, they feel free and act in the way they want, and they are prone to have multiple sexual partners ... . (36 years old, mother, FGD)

Regarding the prevention practice, another mother compared the college students with commercial sex workers:

... In my opinion, commercial sex workers have a better understanding of the disease than the students. They are good at taking care to prevent HIV than college students and they have a better habit of protecting themselves as much as they can ..... (44 years old mother, FGD)

Labor work activity is the most common reason for people to move from place to place in the Majang zone.
Explaining Majang zone as the well-known coffee production center, the participants dictated that people from different places come to the zone for coffee harvesting and income generation. Consequently, the transmission of HIV has continued to be a burning issue because sexual contacts between healthy and infected people are inevitably high in the community where unsafe sexual practices are higher.

A 35 years old health professional stated the situation as:

... There is high labor movement in this area. This area is well known for the production of cash crops. There are many coffee farms and people come here for labor work to plant, or harvest coffee. This contributes for the wide spreading of the disease ... . ( 35 years old, health professional, KII)

Similarly, the majority of the study participants also mentioned the movement of many people from Majang to other neighboring zones for business and mining activities. They may bring new infections to the zone or transmit the virus to people in the other zones.

The majority of the participants in the KIIs agreed that:

... Large numbers of people go to Dima and Mizan (towns of neighboring zones) for labor work, business work, mining, and government works. They also come back to their villages and families. This movement is happening continuously but we don't know what they bring back. We don't know whether they come infected or not ... . (68 years old, community elder, KI)

\section{Discussion}

This study has disclosed the reasons that seem to be contributing to the sustained high prevalence of HIV in the Majang zone of Gambella region, Southwest Ethiopia. The reasons were categorized under five main themes, which include reduced government attention towards prevention and control of HIV, low perceived severity of HIV by the community, substance use, socio-cultural factors, and high movement of people to and from the zone.

Reduced government attention or lack of determination and commitment from the government towards HIV prevention and control activities in recent years was identified as one of the reasons for the high prevalence of HIV among the Majang community. This decline in the focus of the government may be due to the lack or inadequacy of financial resources to be fully committed up to the required level for HIV prevention and control activities. 
This may be due to donor fatigue and shortages in domestic financing for HIV prevention and control.

This is evidenced by the WHO report which states that agencies and governments in developed countries are beginning to suffer from "donor fatigue" induced partly by the realization that the epidemic is unlikely to affect the developed world as badly as was first feared, and partly by an inability to see how the money and effort expended on prevention thus far have affected the course of the epidemic. $^{14}$

Furthermore, according to the United Nations Programme on HIV/AIDS (UNAIDS) report, it is revealed that since 2010 HIV funding from donor governments, other than the US, has declined, and most of the decline can be attributed to decreased bilateral support for HIV. On top of this, future funding from donor governments for HIV remains to be uncertain. ${ }^{15}$

The second major reason identified for the high prevalence of HIV/AIDS among the Majang community was low perceived severity towards HIV. Risk perception towards a certain health condition has a great role in shaping behavior towards that condition. The more the health condition is perceived to be severe, the more individuals tend to take action and vice versa. This is illustrated by the findings from a survey conducted in seven countries on the perception of HIV seriousness, risk, and threat among adult men. ${ }^{16}$

The point here is that the higher perception of the severity of HIV would drive individuals to refrain from risky sexual behaviors like having multiple sexual partners and sexual intercourse without using a condom. ${ }^{17}$ People are more motivated to participate in health-promoting or disease preventive behavior when they perceive that the related health condition is severe. ${ }^{18}$ Furthermore, a study conducted in Taiwan revealed that along with other psychological factors like perceived barriers to condom use, cues to action, perceived susceptibility to HIV, and perceived severity of HIV were significantly associated with risky sexual behaviors among young Thai men. ${ }^{19}$

The third main reason for the high prevalence of HIV/ AIDS was found to be substance abuse, such as chat, alcohol, and hashish in the study area. Alcohol and drug use do not have a direct impact on high HIV prevalence. But the behavior individuals engage in after using alcohol and drugs may increase their exposure to the virus. ${ }^{20}$ Studies conducted in different parts of the world also dictated that alcohol use increases the desire to engage in unprotected sexual intercourse and may delay testing for
HIV, accessing appropriate medical care, and initiating antiretroviral therapy (ART), which may hasten disease progression to full-blown AIDS. ${ }^{21-24}$ In addition, frequent drinkers may also use other drugs that may enhance the risk of direct exposure to HIV, like injection drug use. ${ }^{22}$ The intoxicated HIV-positive individuals may also engage in unprotected sexual intercourse with HIV-negative individuals. ${ }^{23}$

Socio-cultural factors were identified in this study as the fourth contributing factor for the high prevalence of HIV among the Majang community. The presence of "Tifo Bet" in the cultural life of Majang society and the associated practice of unsafe sexual intercourse among local youth, between local youth girls and older adult men coming from the town areas play a crucial role in sustaining the high prevalence and level of HIV transmission in the society.

A simulation study conducted by a team of researchers using a stochastic model to investigate the impact of mixing and concurrency on the spread of a persistent viral STI reported that disassortative sex, ie, sexual partnerships between individuals from high-risk and from low-risk groups (mixing of risk groups) is an important driving force of the HIV epidemic. This is in contrast to assortative sexual mixing, ie, sexual partnerships between individuals of similar HIV risk, which would not foster the spread of HIV. $^{25}$

Intergenerational sex, where young women have sex with older men (more than 5 years age difference), is one of the different forms of disassortative sex. Young people, who have had less exposure to sex, are sexually connected to adults whose HIV infection rates are likely to be higher. ${ }^{26}$ Intergenerational sex may facilitate HIV transmission because of significant power differentials when the ages of the partners are very different, leading to no condom use, manipulation, and a need for economic survival.

Polygamy was mentioned as one of the sociocultural factors contributing to the high prevalence of HIV among the Majang community. This study had found that marrying more than one wife was widely practiced in the area. Studies conducted in $\mathrm{KwaZulu}^{27}$ and Sub-Sahara Africa ${ }^{28}$ also found that polygamy has great contributions to sustained HIV prevalence. However, some other studies conducted on the relation of polygamy and HIV dictated that the prevalence of HIV infection is lower in countries with the high practice of polygyny, and within countries, it is lower in areas with higher levels of polygyny. ${ }^{29,30}$ 
The reasons for this paradoxical finding may be due to socio-cultural differences among the communities. Our study was conducted in a community where the prevalence of HIV is higher with a high movement of people from one area to another area, as indicated in the results part of this paper. However, in the previous studies polygamy was found to be protective for HIV in the communities due to the distinctive structure of sexual networks produced by polygyny, the disproportionate recruitment of HIV positive women into marriages with a polygynous husband, the lower coital frequency in conjugal couples of polygynous marriages, and the restricted access to sexual partners for younger men in populations where polygynous men presumably monopolize the women in their community. ${ }^{29,30}$ However, these factors have not been studied yet in Majang communities. This may call for confirming the association using longitudinal studies.

Last but not least, the high movement of people to and from the Majang community for gold mining, coffee production, mass sport, religious conferences, and other business activities was identified as one of the contributing factors for the sustained high prevalence of HIV in the area. This is in line with a study finding in South Africa, which reported that "circular migration", where individuals cycle through urban and rural areas in search of jobs in urban areas and living a subsistence livelihood in rural areas, has a significant role in the spread of HIV. ${ }^{26}$

This may work through different mechanisms. Labor workers do not bring their spouses, so a vibrant desire for sex and an environment that encourages having extramarital sex, especially with commercial sex workers, is created. This has at least two important implications. First, the individuals may transmit HIV to their sexual partners upon their return back to home. Second, these individuals may also bring HIV infection acquired in their homeland to the labor work areas where they further spread the disease. One study has revealed that despite a scale-up in combination HIV prevention efforts, HIV remains much higher among migrants compared with non-migrants. ${ }^{31}$

Similarly, studies conducted in Sierra Leone and subSaharan African countries found a relatively high magnitude of HIV among miners ${ }^{32}$ and secondary school students, ${ }^{33}$ respectively. This is particularly common in schools where there are poor life skill practices among adolescents and parallel sex education was poor to bring about behavioral change in practicing safe sexual relationships. ${ }^{33}$ This may call for designing continuous social behavioral change interventions and supervisions to control the intertwined behavioral factors for the sustained high prevalence of HIV in the zone.

\section{Strength and Limitations of this Study}

This study has involved various groups of FGD participants and individuals as key informants to get general viewpoints for the sustained prevalence of HIV in the community. Factors identified in this study can be used for designing locally acceptable strategies for the tackling of HIV. However, this study was conducted only in the Majang community. Therefore, the findings may not be generalizable to other communities. Similarly, the study did not involve HIV-positive individuals. The study also did not statistically confirm the association of the identified factors with the prevalence of HIV in the community. Therefore, further quantitative studies are needed in this regard.

\section{Conclusion}

Low government attention towards HIV prevention and control activities, low perceived severity of HIV, substance use, socio-cultural factors, and high movement of people to and from the study area were some of the factors that contributed to high prevalence of HIV in Majang zone. The sociocultural factors include the use of "Tifo Bet" by adolescents and youth for unsafe sexual practices, extramarital sexual practices, and social support for polygamy. These factors either hinder governmental and nongovernmental organizations' interventions to the prevention of HIV or increase the risk of participating in an unprotected sexual activity that increases susceptibility to the virus.

The value of the findings of this paper to the existing knowledge base is that it has identified more distant (distal) factors like the use of "Tifo Bet" which were never reported before in any study. In this regard, we believe that we have identified what lies beneath the tip of the iceberg.

These findings loudly call for the government, nongovernmental, and private sectors to reconsider and strengthen strategies for the prevention of HIV in the study area. The government should find ways of domestic financing for HIV prevention activities and increase its budget share to finance these activities. Integration of HIV prevention activities across all government and private sectors as well as religious institutions is highly recommended. Additionally, sexual and life skill education should be given for adolescents and youth and condoms 
should be made freely available around the "Tifo Bet" to improve access and reduce the risk of unsafe sexual practices.

We would also like to recommend that future researchers, in addition to quantitative study, conduct additional qualitative studies for in-depth analysis of a few more important themes that may not have been addressed in our study.

\section{Acknowledgments}

The authors would like to thank Mizan Tepi University College of Health Science for its kind cooperation in providing stationery materials and duplication of the questionnaire. The authors also like to express their gratitude to Majang Zone Health Department for their genuine cooperation during the fieldwork without whose help the completion of this study would not have been realized. Lastly, the authors would like to thank Dr. Seyoum Aregawi (an English instructor) for his valuable contribution in English editing for grammatical and flow corrections of the manuscript.

\section{Disclosure}

The authors declare that they have no conflicts of interest in this work.

\section{References}

1. AVERT. Global HIV and AIDS statistics |AVERT; 2020. Available from: https://www.avert.org/global-hiv-and-aids-statistics. Accessed November 15, 2021.

2. UNAIDS. UNAIDS Data 2020; 2020.

3. The World Bank. World bank HIV estimates, 2020 [Internet]. 2021 [cited October 21, 2021]. Available from: https://data.worldbank.org/ indicator/SH.DYN.AIDS.ZS. Accessed November 15, 2021.

4. Federal HIV/AIDS Prevention and Control Office. HIV prevention in Ethiopia: national road map; 2018.

5. World Health Organization (WHO). Global health sector strategy on HIV 2016-2021. Towards ending AIDS; 2016.

6. Federal Democratic Republic of Ethiopia; Ministry of Health. Country progress report on the HIV response, 2014. Addis Ababa; 2014.

7. Ethiopian Public Health Institute. HIV related estimates and projections for Ethiopia - 2017. Addis Ababa; 2017.

8. UNAIDS DATA. Joint United Nations Programme on HIV/AIDS (UNAIDS); 2017.

9. Okoboi S, Castelnuovo B, Moore DM, et al. Risky sexual behavior among patients on long-term antiretroviral therapy: a prospective cohort study in urban and rural Uganda. AIDS Res Ther. 2018;15 (1):1-9. doi:10.1186/s12981-018-0203-1

10. Nakiganda LJ, Nakigozi G, Kagaayi J, et al. Cross-sectional comparative study of risky sexual behaviours among HIV-infected persons initiated and waiting to start antiretroviral therapy in rural Rakai, Uganda. BMJ Open. 2017;7(9):1-9. doi:10.1136/bmjopen-2017016954
11. Molla AA, Gelagay AA, Ciccozzi M. Risky sexual practice and associated factors among HIV positive adults attending anti-retroviral treatment clinic at Gondar University Referral Hospital, Northwest Ethiopia. PLoS One. 2017;12(3):1-12. doi:10.1371/journal.pone. 0174267

12. Tadesse WB, Gelagay AA. Risky sexual practice and associated factors among HIV positive adults visiting ART clinics in public hospitals in Addis Ababa city, Ethiopia: a cross sectional study. BMC Public Health. 2019;19(1):4-11. doi:10.1186/s12889-0196438-5

13. Wondimu W, Asefa A, Qanche Q, Tadesse Nigussie T. Determinants of the community knowledge and attitude towards HIV prevention methods in Majang Zone, Southwest Ethiopia. HIV/AIDS. 2021;13:21.

14. Cohen B, Trussell J. Preventing and Mitigating AIDS in SubSaharan Africa. Washington, DC: The National Academies Press; 1996.

15. Kates J, Wexler A, Lief E. Donor government funding for HIV in low- and middle-income countries in 2018; 2019.

16. Chard AN, Metheny N, Stephenson R, Ingalls N. Perceptions of HIV seriousness, risk, and threat among online samples of HIV-negative men who have sex with men in seven countries. JMIR Public Health Surveil. 2017;3:e7546. doi:10.2196/ publichealth. 7546

17. Glanz K, Rimer BK, Viswanath K, editors. Health Behavior and Health Education: Theory, Research, and Practice. 4th ed. San Francisco: Jossey-Bass; 2008.

18. Abraham C, Sheeran P. The health belief model. In: Conner M, Norman P, editors. Predicting Health Behaviour: Research and Practice with Social Cognition Models. 2nd ed. Maidenhead: Open University Press; 2005:28-80.

19. Khumsaen N, Stephenson R, Sciences B, Arbor A, Arbor A. Beliefs and perception about HIV/AIDS, self-efficacy, and HIV sexual risk behaviors among young Thai men who have sex with men Natawan. AIDS Educ Prev. 2019;29(2):175-190. doi:10.1521/aeap.2017. 29.2.175

20. Singh RK, Patra S. What factors are responsible for higher prevalence of HIV infection among urban women than rural women in Tanzania? Ethiop J Health Sci. 2011;25(4):321-328. doi:10.4314/ ejhs.v25i4.5

21. Rehm J, Shield KD, Joharchi N, Shuper PA. Alcohol consumption and the intention to engage in unprotected sex: systematic review and meta-analysis. Addiction. 2011;107:51-59. doi:10.1111/j.1360-0443. 2011.03621.x

22. Bryant KJ, Ph D, Nelson S, Braithwaite RS, Roach D. Integrating HIV/AIDS and alcohol research. Alcohol Res Health. 2010;33 (3):167-178.

23. Kiene SM, Simbayi LC, Abrams A, Tennen H, Fisher JD. High rates of unprotected sex occurring among HIV-positive individuals in a daily diary study in South Africa: the role of alcohol use. J Acquir Immune Defic Syndr. 2009;49(2):219-226. doi:10.1097/ QAI.0b013e318184559f

24. World Health Organization (WHO). Alcohol Use and Sexual Risk Behaviour: A Cross-Cultural Study in Eight Countries. Geneva; 2005.

25. Doherty IA, Shiboski NS, Ellen JM, Adimora AA, Padian NS. Sexual bridging socially and over time: a simulation model exploring the relative effects of mixing and concurrency on viral sexually transmitted infection transmission. Sex Transm Dis. 2006;33(6):368-373. doi:10.1097/01.olq.0000194586.66409.7a

26. Muula AS. HIV Infection and AIDS Among Young Women in South Africa.Croat Med J. 2008;49:423-435. doi:10.3325/cmj.2008.3.423

27. Nyathikazi TJL. Investigating the association between HIV/AIDS and polygamy. Stellenbosch University; 2013.

28. Loosli C. Traditional practices and HIV prevention in Sub-Saharan Africa. Geneva; 2004. 
29. Reniers G, Watkins S. Polygyny and the spread of HIV in Sub Saharan Africa: a case of benign concurrency. NIH Public Access. 2011;24(2):299-307.

30. Reniers G, Tfaily R. Polygyny, Partnership Concurrency, and HIV Transmission in Sub-Saharan Africa. Demography. 2012;49(3):10751101. doi:10.1007/s13524-012-0114-z

31. Cassels S. Comment Time, population mobility, and HIV transmission. Lancet HIV. 2020;3018:19-21.
32. Cham A. Mining and HIV/AIDS Transmission Among Marampa Mining Communities in Lunsar, Sierra [Walden Dissertations and Doctoral Studies Collection]; 2015.

33. Lucas AM, Wilson NL. Scholing, wealth, risky sexual behavior, and HIV/AIDS in Sub-Saharan Africa. Cambridge; 2018.

\section{Publish your work in this journal}

The Journal of Multidisciplinary Healthcare is an international, peerreviewed open-access journal that aims to represent and publish research in healthcare areas delivered by practitioners of different disciplines. This includes studies and reviews conducted by multidisciplinary teams as well as research which evaluates the results or conduct of such teams or healthcare processes in general. The journal covers a very wide range of areas and welcomes submissions from practitioners at all levels, from all over the world. The manuscript management system is completely online and includes a very quick and fair peer-review system. Visit http://www.dovepress.com/testimonials. php to read real quotes from published authors. 